\title{
MODCEL: an integrated cell model for river basin simulation
}

\author{
F. C. B. Mascarenhas, M. G. Miguez \& L. P. C. Magalhães \\ Computational Hydraulics Laboratory, \\ Federal University of Rio de Janeiro, Brazil
}

\begin{abstract}
The assessment of catchment behaviour is a complex issue and constitutes a valuable tool for water resources management. The aim of this paper is to present the theoretical basis of MODCEL, an integrated program for river basin simulation composed by three different models that perform hydrodynamic, hydrologic and water quality simulation, also allowing representation of water users' withdrawal, wastewater discharge and operation of hydraulic structures. The main engine of MODCEL is based on a hydrodynamic cell model. This hydrodynamic model represents the basin through a cell network in order to produce a looped discharge net to simulate flow patterns. The hydrologic model performs rainfall-runoff simulation and works as a lumped model in each cell of the domain region, although it can be variable from cell to cell. The water quality model is based on a lagrangean approach and applies for the transport of particles that represent conservative or nonconservative substances. The developed program can be used in many different applications, such as rainfall-runoff simulation and flood routing, among others. Finally, a case study applied to the Paraiba do Sul river basin in Brazil is presented.

Keywords: cell model, hydrologic modelling, river basin simulation.
\end{abstract}

\section{Introduction}

Water resources management depends on the assessment of quantitative and qualitative issues regarding river basins. In this context, mathematical models can provide an important support tool for this analysis.

MODCEL is a computer program developed for river basin simulation. It is composed by three models which are responsible for hydrodynamic, hydrologic 
and water quality simulation. MODCEL can be employed in a wide range of water resources engineering studies, varying according to application goals, and time and spatial scale. It is capable of carrying on small catchments urban floods simulations as well as long-term hydrologic and hydrodynamic simulation of large and complex river basins.

The original version of this program was composed basically by the unsteady hydrodynamic model developed by Mascarenhas and Miguez [1] using the concept of flow cells (Zanobetti et al. [2]). The aim of the original model was flood routing in large floodplains environments. As time passed, new features were added to the model, increasing its representation capability and, therefore, allowing the development of new applications. This paper presents the evolution of MODCEL features regarding hydrologic modelling and simulation of large river basins. In this context, some characteristics concerning urban flood applications and other details of MODCEL were not included in this paper and can be found on Mascarenhas and Miguez [1] and Mascarenhas et al. [3].

\section{Basic characteristics of MODCEL}

The basic hypothesis of this model is that a river basin can be modelled through a set of linked homogeneous compartments, called flow cells. A cell can communicate with others through links, in such an arrangement that is capable of providing a spatial topographic and hydraulic representation of the basin.

In fact, the basic elements considered by MODCEL are cells and links. Every cell has a flow centre, which is taken as a reference for the topographic representation. In a cell, water surface profile and stored volume are assumed to be directly related to the water depth at its centre. In this context, mass conservation law is applied to each cell. Cells are also arranged in a topological scheme, which is used in the numerical solution through the double sweep method. While cells represent sub-areas and account for storage processes, links are responsible for flow between cells. An extent list of flow links is available in order to allow the representation of several flow patterns. Therefore, the capacity of this program in simulating different river basins characteristics is achieved through the variety of cell and link types.

One highlight feature of MODCEL is the integration of hydrodynamic, hydrologic and water quality models. This integration is done through the exchange of outputs and parameters between these models. In this way, the hydrologic model is the first to run and calculates discharge time series at cell flow centres. In the sequence, the hydrodynamic model can determine resulting flows and velocities through cell links. Finally, the water quality model makes use of hydrodynamic model outputs (water storage in the cells; velocity fields and hydrographs at the links) and its own parameters in order to calculate the concentration along the time of any interest substance at cell centres. Water use module defines characteristics of water users withdrawal and wastewater disposal and operation of hydraulic structures, such as hydroelectric plants or diversion structures. Figure 1 illustrates the interactions between the models that constitute MODCEL. 

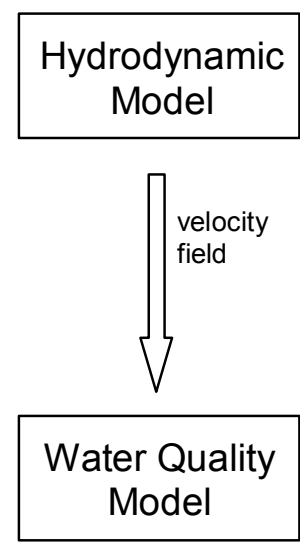
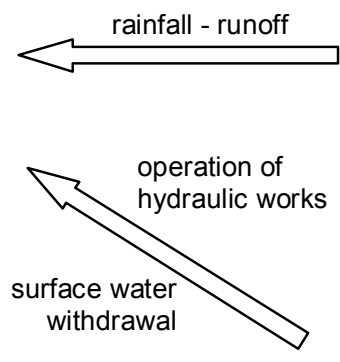

Wastewater disposal

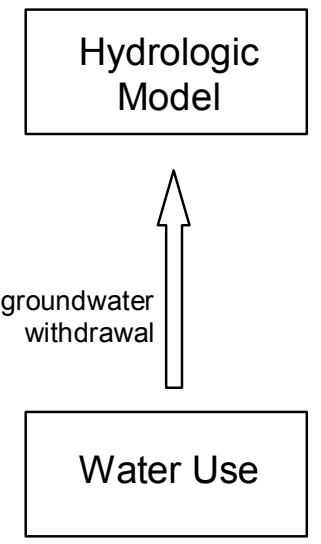

Figure 1: $\quad$ Simplified representation of interactions between the main models of MODCEL.

The set of cell types available in MODCEL for large river basin applications is listed below:

- river or channel cells - this type of cell is used to model the main open channel drainage flow, in which the cross section is taken as rectangular and may be simple or compound;

- regular surface cells - these cells are similar to the previous one, however, having prismatic shape;

- reservoir cells - used to simulate water storage in a temporary pond or reservoir, which presents an elevation versus surface area curve.

\section{Hydrodynamic model}

The hydrodynamic model uses the mass conservation law and hydrodynamic relations as the core engine of MODCEL. The water level variation in a cell i, at a time interval $t$, is given by the continuity equation applied for that cell as stated in eqn (1).

$$
A_{S_{i}} \frac{d Z_{i}}{d t}=P_{i}+\sum_{k} Q_{i, k}
$$

In which:

$Q_{i, k}$ is the discharge between neighbouring cells i and $\mathrm{k} ; Z_{i}$ is the water surface level at the centre of the cell $\mathrm{i} ; A_{S_{i}}$ is the water surface area for the cell $\mathrm{i} ; P_{i}$ is the discharge related to the rainfall over the cell; and $t$ is a independent variable related to time. 
Flow between cells can be evaluated through known one-dimensional hydraulic laws, like the Saint-Venant dynamic equation, in its complete form or in a simplified one, the free or drowned weirs equation, among others. Discharge between two adjacent cells is considered as a function of the water levels at their centres, in any time.

Typical flow links available in MODCEL for large river basin applications are listed bellow:

- $\quad$ river link - this type of link is related to river and channel flows, and corresponds to the free surface flow represented by the Saint-Venant dynamic equation;

- $\quad$ surface link - this type of link represents the Saint-Venant dynamic equation without inertia terms and is frequently used to represent flow over floodplains and overland flow;

- broad crested weir link - this link represents the flow over broad-crested weirs and is used, mainly, to represent the flow between a river and its floodplain;

- reservoir link - this link combines an orifice, as the outlet discharge of a reservoir, with a weir, that can enter or not in charge, depending on reservoir operation.

\section{Hydrologic model}

Rainfall-runoff modelling was originally represented in MODCEL through the use of runoff coefficient method. Thus, for a given time interval, the rainfall excess in any cell could be obtained by multiplying its runoff coefficient by the rainfall occurred during that period. Later, a second hydrologic model was developed. That approach considered the application of a reservoir to account for initial abstraction losses and the use of phi-index method to represent potential infiltration. These two models are event based and focus only on the determination of runoff in small catchments. In order to allow hydrologic modelling of large river basins it was required to develop a new model with different characteristics.

The new hydrologic model developed for MODCEL works as a deterministic, lumped, conceptual, continuous time, fitted-parameter rainfall-runoff applied to each cell of the domain region. Rainfall and simulation parameters can be variable from cell to cell. Two main characteristics of this hydrologic model are its simplicity and its small number of parameters. Perrin et al. [4] argue that simple models can achieve a level of performance almost as high as those with a large number of parameters. For every time step, the calculations related to the hydrologic model routines are performed first and then routing is done through the hydrodynamic routines. The following processes are represented in this hydrologic model: rainfall; initial abstraction losses; runoff; infiltration; interflow; percolation; baseflow; evapotranspiration and water surface evaporation. Figure 2 illustrates a general sketch of this hydrologic model. 


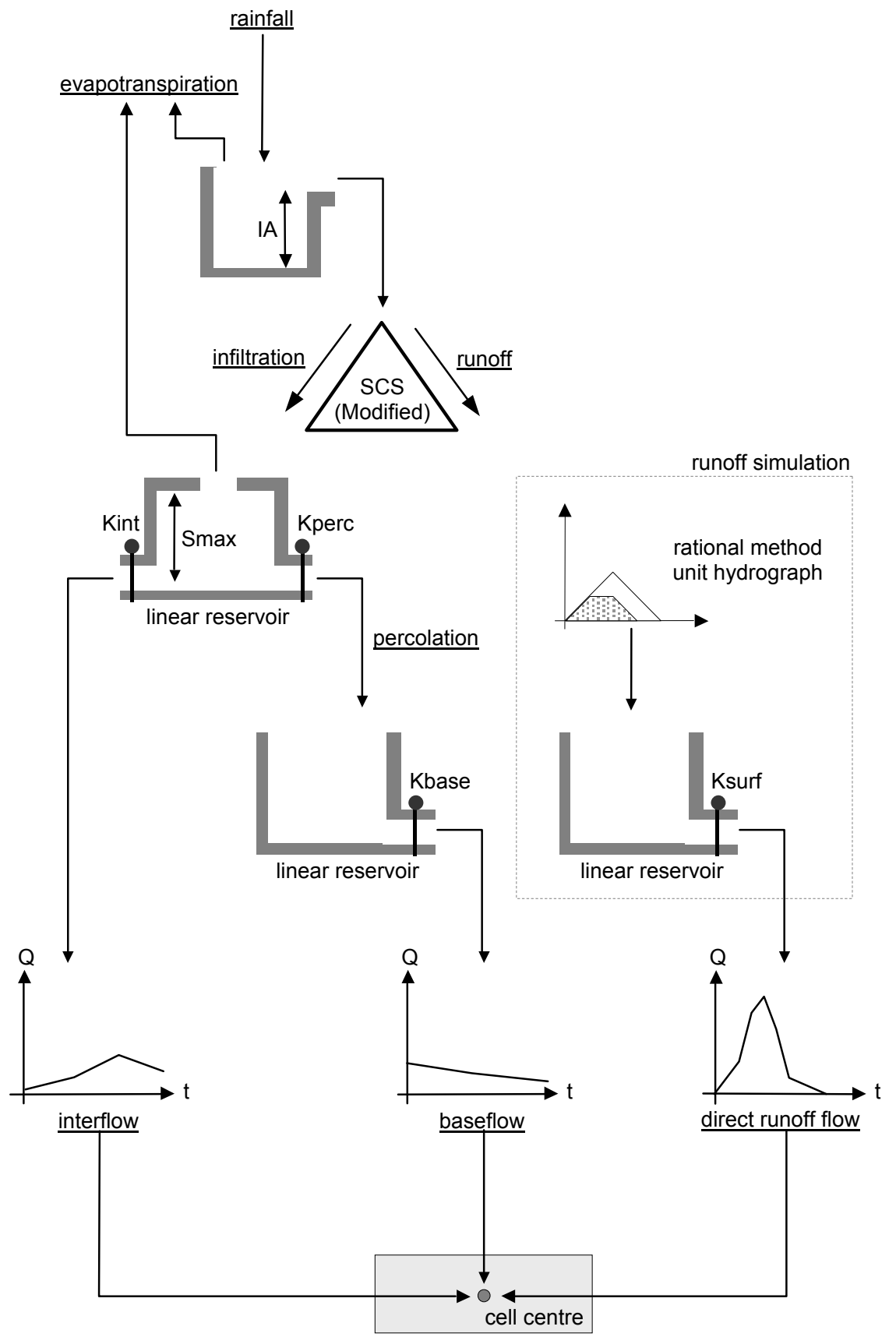

Figure 2: Simplified hydrologic model sketch. 


\subsection{Rainfall}

Rainfall is a basic input for the simulation of this hydrologic model and is applied for each cell. It is represented as a file containing a sequence of precipitation along time steps. Thus, rainfall records or forecasts need to be adapted to time grid. The definition of rainfall for each cell must be done previously to the simulation and can be carried out, for instance, through the analysis of spatial distribution of available rain gauges and their data.

\subsection{Rainfall excess}

An adaptation of the Soil Conservation Service (SCS) Curve Number (CN) model is employed in the estimation of precipitation excess. This method considers cumulative direct runoff as a function of cumulative precipitation, soil cover, land use, and antecedent moisture (SCS [5]). Ponce and Hawkins [6] discuss this method's advantages and disadvantages.

The original SCS method is event based. MODCEL's approach adapted this model in order to allow continuous time simulation. These changes consist in the resetting of cumulative direct runoff and cumulative precipitation to zero after time period without rain. The simulation parameter of this process is the $\mathrm{CN}$ value.

\subsection{Abstraction losses}

Canopy interception and depressions storage are represented in a combined way as an abstraction reservoir. This reservoir capacity can be prescribed by model user as a certain abstraction depth or even estimated through methods such as the SCS. Rainfall is first applied to this reservoir. As long as it is not full, an amount of the precipitation can be stored. A state variable controls the storage in this reservoir through time.

\subsection{Runoff simulation}

Once precipitation excess is calculated for each time interval, the following step is the determination of direct runoff hydrograph, which is applied to the cell flow centre. Runoff simulation account is done through a combination of two methods: rational method unit hydrograph (RMUH) and application of a linear reservoir routing. RMUH is a simple and common method used for runoff simulation in small catchment areas. One main advantage of this method is that its response does not vary according to adopted time grid. The hydrograph related to a time step assumes a trapezoidal shape as illustrated in figure 3 . The disadvantage of this method is that it frequently overestimates flows, especially as catchment area (in this case, cell area) increases. In order to avoid this undesirable effect, the response obtained with RMUH is then routed through a linear reservoir. The simulation parameters used in these processes are cell time of concentration (from its upstream reaches to its centre) and the surface linear reservoir recession constant. 


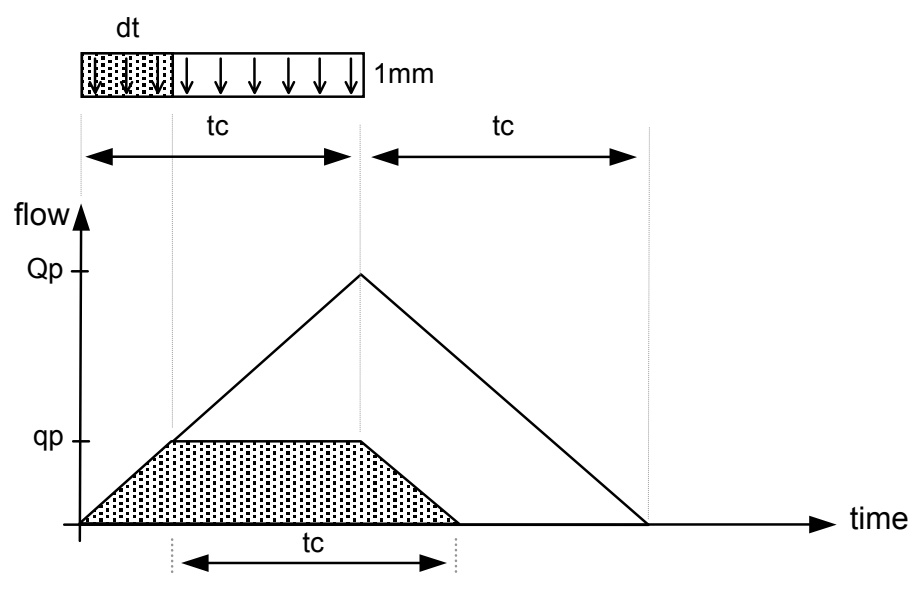

Figure 3: Rational method unit hydrograph.

\subsection{Percolation and interflow}

The infiltration depth during a time step defines an infiltration rate. This infiltration rate is the main input applied to the sub-surface reservoir. This reservoir maximum capacity is calculated through the SCS method "S" parameter. Two outputs from this reservoir are considered, one of which represents percolation flow to a lower soil layer while the other accounts for interflow rates. Both flows are modelled as linear reservoir outputs. Evapotranspiration rate is another outflow that is removed from this reservoir. Thus, the mass conservation equation applied to this reservoir can be written as:

$$
I_{\text {inf }}-O_{\text {int }}-O_{\text {perc }}-E_{\text {subsurface }}=\frac{d S_{s s}}{d t}
$$

In which: $I_{\text {inf }}$ is the infiltration rate; $O_{\text {int }}$ is the interflow output; $O_{\text {perc }}$ is the percolation output; $E_{\text {subsurface }}$ is the evaporation rate applied to the subsurface reservoir; and, $S_{s s}$ is a storage state variable.

Developing eqn. (2) through the finite difference method, it is obtained:

$$
S^{t+1}=\frac{2 \cdot \Delta t \cdot K_{\text {perc }} \cdot K_{\mathrm{int}}}{2 \cdot K_{\text {perc }} \cdot K_{\mathrm{int}}+\Delta t \cdot\left(K_{\text {perc }}+K_{\mathrm{int}}\right)} \cdot\left[\left(\frac{1}{\Delta t}-\frac{1}{2 \cdot K_{\text {perc }}}-\frac{1}{2 \cdot K_{\mathrm{int}}}\right) \cdot S^{t}+\bar{I}_{\mathrm{inf}}-\bar{E}_{\text {subsurface }}\right]
$$

in which: $S^{t+1}$ is the storage in time $\mathrm{t}+1 ; S^{t}$ is the storage in time $\mathrm{t} ; \Delta t$ is the time step length; $K_{\text {perc }}$ is the linear reservoir recession constant related to percolation; $K_{\text {int }}$ is the linear reservoir recession constant related to interflow; $\bar{l}_{\text {inf }}$ is the mean 
infiltration rate between $\mathrm{t}$ and $\mathrm{t}+1$; and, $\bar{E}_{\text {subsurface }}$ is the mean evaporation rate between $\mathrm{t}$ and $\mathrm{t}+1$.

\subsection{Baseflow}

Baseflow is also modelled as a linear reservoir output. In this case, the reservoir represents groundwater storage and percolation rate is considered as its basic input. The simulation parameter related to this process is the baseflow linear reservoir recession constant.

\subsection{Evapotranspiration}

Potential evapotranspiration is represented as a monthly-varied record. In order to determine real evapotranspiration rates, the following procedure is applied. Water stored in the abstraction reservoir is the primary source for evapotranspiration. Water in the subsurface reservoir is its secondary source. If the primary source is not capable of fulfilling potential evapotranspiration rate, water stored in the abstraction reservoir is removed and a fraction of the additional evaporation depth is subtracted from the secondary source. The fraction is equal to the filling percentage of the subsurface reservoir.

\subsection{Water surface evaporation}

Water surface evaporation rate is represented as a monthly-varied record and applies only for river and reservoir type cells. In a given time step, evaporation flow is determined by multiplying surface area by this rate.

\section{Water quality model}

A water quality model compatible with MODCEL's structure has been developed and is currently under final test phase. A lagrangean approach was used for modelling the transport of substances. Thus, particles are used to represent a finite quantity of mass of the interest substance. Particles are stored into cells and can move from cell to cell through links. In a given time step, a particle suffers an advective transport that can be determined as the multiplication of the time step length by the instantaneous velocity calculated by the hydrodynamic model for the link through which the particle is moving. The transport related to dispersion is determined as a random component. The model is able to represent conservative and nonconservative substances, although only first order decay kinetics is available for now. The reason for this is that in most of the applications for which this model was designed the most important pollutant is BOD, whose decay can be adequately modelled through that kind of kinetic relationship (Thomann and Mueller [7], Streeter and Phelps [8]). Further details about this model will be provided after the conclusion of the test period and the development of a case study application. 


\section{Water users and hydraulic structures operation}

Other new features added to MODCEL concern the representation of water users and hydraulic structures operation. These features were developed in order to enhance MODCEL's representation capability and make it suitable for carrying out water resources management studies, e.g., local and regional impact analysis of water users' withdrawal permits.

\subsection{Water users}

Water user's profile varies a lot according to different aspects. In this context, it is difficult or even impossible to obtain a general sketch for water users' representation. A methodology that can be applied to represent typical water users' quantity and quality local effects was developed for MODCEL.

Water users can be represented through its withdrawal flow, wastewater flow and wastewater pollutant concentration. The number of pollutants can be as many as required for the application. Existent water users and their characteristics are considered as a cell property and, therefore, withdrawal and wastewater disposal are assumed to occur at the cell centre. The difference between withdrawal and wastewater flows is equal to the amount of water consumed by the user in any time step. For any pollutant or substance and time interval, the difference between withdrawal loads (withdrawal flow multiplied by pollutant concentration in the cell) and wastewater load (wastewater flow multiplied by wastewater pollutant concentration) accounts for the load balance, which may act as a source or a sink.

This methodology is suitable for a typical industry user representation, but is not so good for modelling an agriculture user, for instance. Future developments intended for water users' representation in MODCEL is the creation of different water user types (with different modelling sketches), the possibility of groundwater withdrawal (which will be pointed for the hydrologic model and removed from groundwater reservoir) and the introduction of seasonal withdrawal and wastewater variation. This last feature will allow studies regarding seasonal water permits modelling. Figure 4 illustrates water users' representation in MODCEL.

\subsection{Hydroelectric plants operation}

MODCEL represents hydroelectric plant operation as two separate components: regular flow operation and spillway operation. Regular flow operation is equal to the sum of the flow that goes through the penstocks (and generate hydropower) and the flow released through bottom discharges.

MODCEL's user defines regular flow. This flow is modelled as a sequence of daily operation types. Each daily operation type is represented as a sequence of hourly discharge flow.

Spillway operation is represented as a sequence of values for the relation water level versus spillway discharge. Linear interpolation is performed between specified points of this curve. 


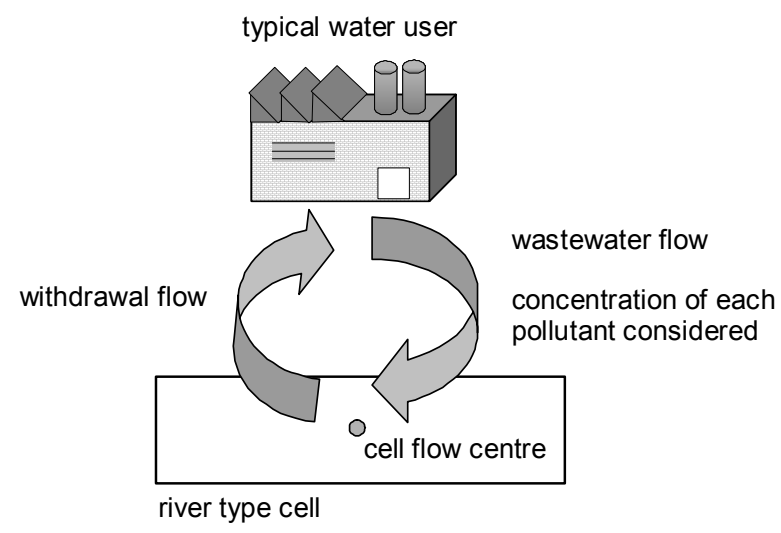

Figure 4: $\quad$ Representation of water users.

\subsection{Diversion structures}

Diversion structures are represented as constant flow diversion between two cells, one of which loses water and the other receives this flow. It is intended to develop seasonal variable diversion flows in future versions of MODCEL.

\section{Case study}

Case study presented here refers to Paraiba do Sul river basin, located in the southeastern of Brazil, one of the most important economic regions of this country. This basin presents a drainage area of $55,500 \mathrm{~km}^{2}$ and an approximate main watercourse length of $1,150 \mathrm{~km}$. This river basin constitutes a complex system as there are four major hydroelectric plants (and several other small capacity plants), a large size water diversion structure that provides water for the metropolitan region of Rio de Janeiro city $\left(\sim 160 \mathrm{~m}^{3} / \mathrm{s}\right.$ diversion flow) and thousands of water users. Figure 5 shows the location of this river and presents a plain view of its basin.

Cell division of the study area considered the use of large cells to represent sub-basins and reservoirs and smaller cells to model river reaches. Five different sub-basins (with drainage area varying from approximately $200 \mathrm{~km}^{2}$ to $2000 \mathrm{~km}^{2}$ ) with river gauges located close to its output were employed for the calibration of the hydrologic model. These calibrations considered one-year flow records. Figure 6 illustrates the cell division of the basin. Figure 7 shows calibration results for Piabanha river basin $\left(2065 \mathrm{~km}^{2}\right)$.

The set of calibration parameters fitted for these cells were also verified for a different year. After that, these parameters were extended to other cells that were not calibrated. Finally, it was developed a comparison between observed and simulated flows for river gauges located at the main channel of Paraiba do Sul river. It was observed a $10 \%$ maximum error in the adjustment of mean annual flow during calibration and verification. 

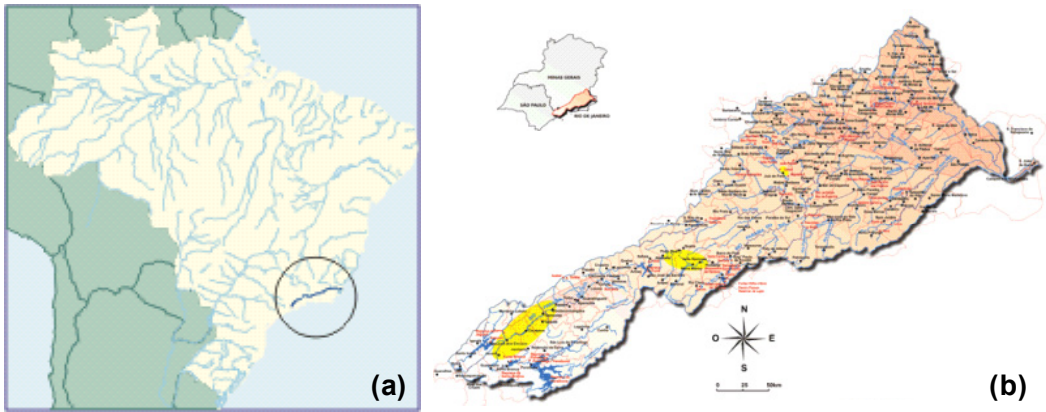

Figure 5: (a) Location of the study area in Brazil; (b) Paraiba do Sul river basin.

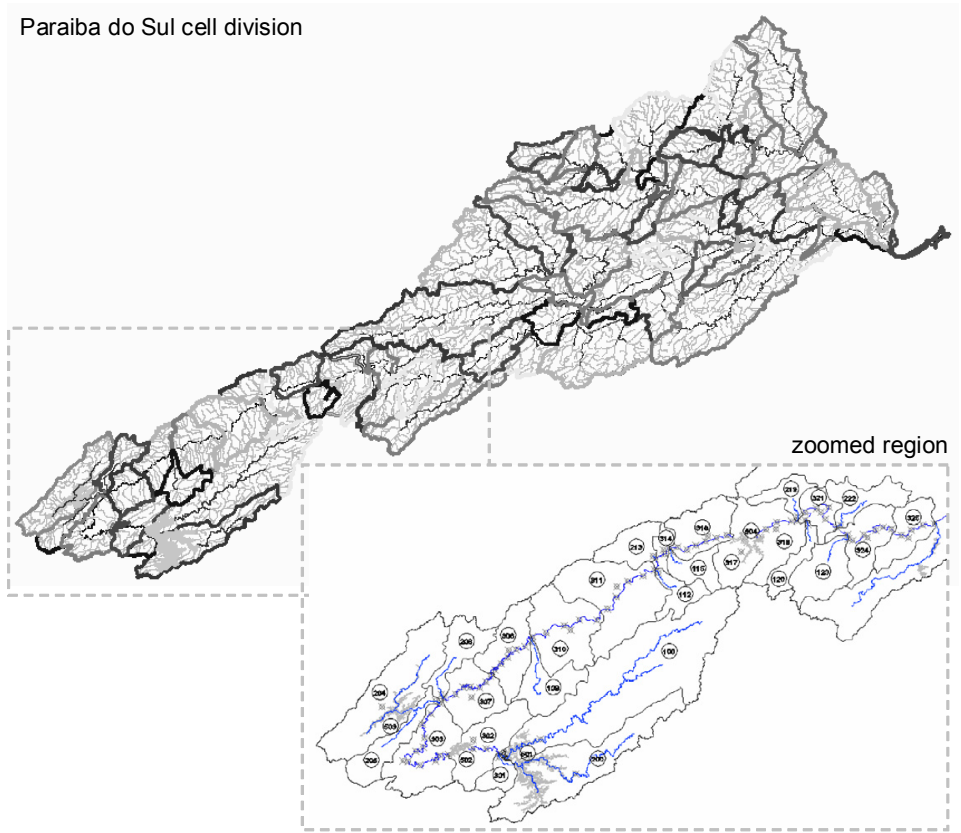

Figure 6: Cell division of Paraiba do Sul basin.

\section{Concluding remarks}

This paper presented MODCEL as a river basin simulation tool. The results achieved in the simulation of Paraiba do Sul River show the potential capability of MODCEL to represent mathematically the behaviour of a complex system. One of the highlights of this tool is the integration, in a single program, of different purposes models that perform hydrodynamic, hydrologic and water 
quality simulation. In the future, it is possible to continue improving its capacity to represent river basin features by developing individual model structures and new types of links and cells.

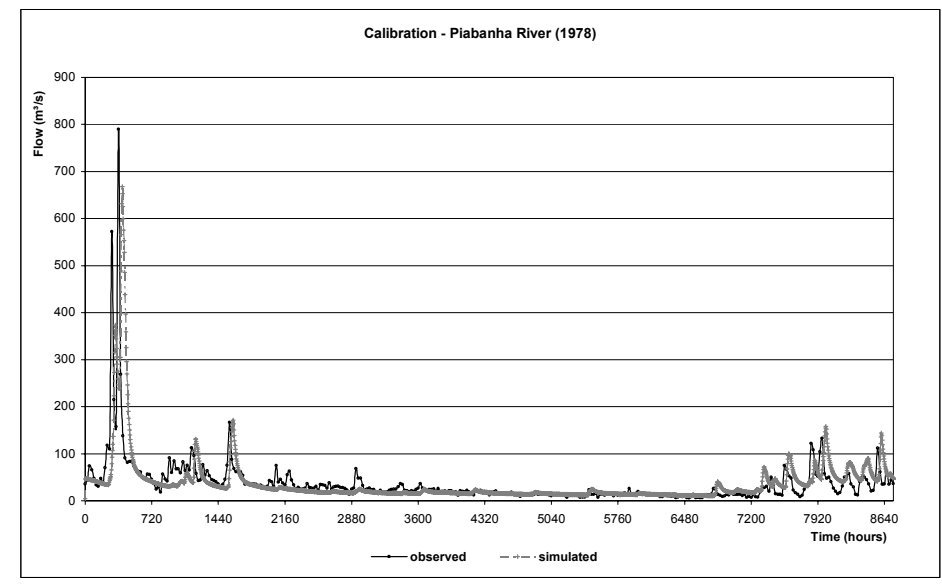

Figure 7: Calibration result for Piabanha basin cell.

\section{References}

[1] Mascarenhas, F.C.B. and Miguez, M.G.; Urban Flood Control through a Mathematical Cell. Water International, Vol. 27 (2), 208-218, 2002.

[2] Zanobetti, D.; Lorgeré, H.; Preissman, A.; Cunge, J.A.; Mekong Delta Mathematical Program Construction. Journal of the Waterways and Harbours Division, ASCE, Vol. 96 (2), 181-199, 1970.

[3] Mascarenhas, F.C.B.; Toda, K.; Miguez, M.G.; Inoue, K.; Flood Risk Simulation. WIT Press, Gateshead, UK, 2005.

[4] Perrin, C.; Michel, C.; Andréassian, V.; Does a Large Number of Parameters Enhance Model Performance? Comparative Assessment of Common Catchment Model Structures on 429 Catchments. Journal of Hydrology 242, 275-301, 2001.

[5] SCS. Urban Hydrology for Small Watersheds, Technical Release 55. USDA, Springfield, VA, 1986.

[6] Ponce, V.M. and Hawkins, R.H.; Runoff curve number: Has it reached maturity?" Journal of Hydrologic Engineering, ASCE, 1(1), 11-19, 1996.

[7] Thomann, R.V. and Mueller, J.A.; Principles of Surface Water Quality Modeling and Control. Harper International Edition. New York, USA, 1987.

[8] Streeter, H.W. and Phelps, E.B.; A Study of the Pollution and Natural Purification of the Ohio River. Public Health Bulletin, 146, Washington, USA, 1925. 